\title{
Comparative Analysis of Controller Tuning Techniques for Dead Time Processes
}

\author{
Parvesh Saini*, Charu Sharma \\ Department of Electrical Engineering \\ Graphic Era Deemed to be University, Dehradun, Uttarakhand, India \\ *Corresponding author: parv1606@gmail.com, parvesh.saini.eee@geu.ac.in \\ (Received May 31, 2018; Accepted January 21, 2019)
}

\begin{abstract}
Dead time processes are present in various industries at different levels. In certain situations, it is difficult to control such processes using conventional tuning techniques. Due to the need of precise control, robust tuning techniques are under development. This paper presents the design and comparative analysis of various PID tuning techniques for dead time process. The tuning techniques used to design PI and PID controller are Zeigler - Nichols, Tyreus - Luyben, Internal Model Control (IMC) and Extended Forced Oscillation (EFO) technique. The comparison is done on the basis of time response, frequency response (gain margin and phase margin) and performance indices (ISE, IAE, ITSE, ITAE).
\end{abstract}

Keywords- PID controller, Internal Model Control (IMC), Zeigler-Nichols (ZN), Tyreus-Luyben (TL), Extended Forced Oscillation (EFO).

\section{Introduction}

Most of the industrial processes exhibit dead time. Even the economical and biological systems exhibit dead time. A major cause of dead time in processes is processing time of sensors, due to the transportation of mass, energy or information and a series connection of a large number of low order systems (Normey-Rico, 2007). Limitation of dead time in a process is that the stability margins of system decreases and hence, in the presence of dead time, it is difficult to design controllers (Shi and Lee, 2002; O'Dwyer, 2006; Normey-Rico, 2007). The most common dead time processes that are encountered in industries are First Order Dead Time Processes (FOPDT). Design of controller for dead time processes has been an interesting area for researchers for the last few decades. Performance analysis of controllers for dead time processes has been done by researchers on the basis of various aspects. Such as Juneja et al. (2010), Juneja and Ray (2013) in a performance comparison of various controllers for a FOPDT process have been described. Similarly, Chauhaan et al. (2014) also presented a comparative analysis of various tuning techniques for the FOPDT process. Chaturvedi and Juneja (2013) present the effect of approximation of dead time on the performance of the controller for a second order delay time process. Naithani et al. (2017) present a comparative analysis of various controller tuning techniques for a FOPDT process based on integral error criterion. Schneider (1988) evaluates the performance of three major controllers (conventional PI, Smith predictor and CGST controller) for dead time processes. Similarly, there are numerous techniques proposed by various researchers in the last few decades for dead time processes. Such as in Vilanova and Balaguer (2006) an ISA-PID based tuning of PID controller has been proposed, O'Dwyer (2006) presented a survey of various PI and PID tuning techniques for dead time systems. Shi and Lee (2002) proposed an effective PID tuning technique for FOPDT processes to achieve the desired phase margin. Similarly, Bazanella et al. (2017) proposed a novel technique of PI and PID tuning for systems without critical frequencies. However, through results, it has been shown that the 
International Journal of Mathematical, Engineering and Management Sciences

Vol. 4, No. 3, 803-813, 2019

https://dx.doi.org/10.33889/IJMEMS.2019.4.3-063

technique is effectively applicable to FOPDT systems. Likewise, there are a number of PI and PID tuning techniques available for dead time processes for optimal time and frequency responses.

However, in this paper, a comparison of four major PI and PID tuning techniques have been presented for a FOPDT process. The FOPDT process and tuning techniques have been discussed in the next section.

\section{System and Controller Design}

The dead time process taken for this work is the consistency of headbox (Sell, 1995). The process model is a FOPDT model and is given as:

$$
G(s)=\frac{0.03}{10 s+1} e^{-s}
$$

Its Pade's approximated model is given by:

$$
G_{\text {Pade's }}(s)=\frac{-0.015 \mathrm{~s}+0.03}{5 \mathrm{~s}^{2}+10.5 \mathrm{~s}+1}
$$

Consistency is one of the crucial parameters related to the paper machine. Consistency is taken into consideration at various levels such as at the input (consistency of the pulp), consistency of pulp flow, output consistency etc. To produce the paper of desired quality, consistency of pulp at a various level has to be maintained. The FOPDT model is approximated using Pade's approximation. The approximated model is given by equation 2. In this work, the controllers have been designed for both models using tuning techniques as discussed below.

\subsection{Zeigler Nichols Technique (Ziegler et al., 1942)}

This technique was proposed by J. G. Ziegler and N. B. Nichols in 1942 for tuning of controller popularly known as $\mathrm{ZN}$ tuning. This is the most widely used controller tuning method. There are two $\mathrm{ZN}$ tuning techniques available. First is open loop $\mathrm{ZN}$ tuning technique and second is closed loop $\mathrm{ZN}$ tuning technique. Closed loop $\mathrm{ZN}$ tuning technique is based on the determination of ultimate gain and period of the given system. Controller parameters are obtained based on the values of ultimate parameters.

\subsection{Tyreus - Luyben Technique (Tyreus and Luyben, 1992; Luyben, 1996; Luyben and Luyben, 1997)}

This technique is similar to $\mathrm{ZN}$ tuning technique proposed by Tyreus and Luyben (1992). Commonly known as TL tuning technique, this method is also based on the knowledge of ultimate parameters of the given system.

\subsection{Internal Model Control Technique (Rivera et al., 1986; Morari and Zafiriou, 1989; Chien and Fruehauf, 1990; Skogestad, 2003; Saxena and Hote, 2016)}

Rivera et al. (1986); Morari and Zafiriou (1989), have proposed a more robust and stable controller tuning technique based on the internal model formulation of the given system. Popularly known as IMC tuning technique, this method is applied to some selective processes 
International Journal of Mathematical, Engineering and Management Sciences

Vol. 4, No. 3, 803-813, 2019

https://dx.doi.org/10.33889/IJMEMS.2019.4.3-063

models (Chien and Fruehauf, (1990). In this method, the robustness of the controller is based on the selection of design parameter " $\tau_{c}$ ". The instructions regarding the selection of " $\tau_{c}$ " are described in (Rivera et al., 1986; Chien and Fruehauf, 1990; Skogestad, 2003). The basic structure of IMC is shown in Figure 1.

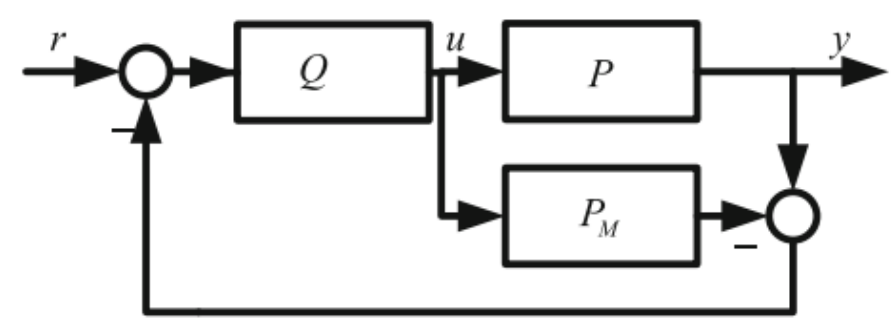

Figure 1. Internal model control basic structure (Saxena and Hote, 2016)

\subsection{Extended Forced Oscillation Technique (Bazanella et al., 2017)}

This is the latest technique of PI and PID tuning proposed by Bazanella et al. (2017). Unlike ZN tuning technique, this method proposes tuning values for models which do not exhibit ultimate parameters. However, this method is satisfactorily applicable to systems with the ultimate period and frequency.

Based on the above-discussed tuning techniques, PI and PID controllers have been designed for model given in equation 1 and 2. The controller design is discussed below:

The critical parameters of the given system are:

Critical frequency $\left(\omega_{u}\right)=2.1 \mathrm{rad} / \mathrm{sec}$,

Critical Gain $\left(k_{u}\right)=699.842$,

Critical Period $\left(P_{u}\right)=2.992$ sec.

The tuning values of various tuning techniques have been depicted in Tables 1 to Table 4 below:

Table 1. ZN tuning values

\begin{tabular}{|c|c|c|c|}
\hline Controller & Kp & $\mathrm{Ti}$ & $\mathrm{Td}$ \\
\hline ZN - PI & 315.36 & 2.5 & -- \\
\hline ZN - PID & 420.47 & 1.5 & 0.37 \\
\hline
\end{tabular}

Table 2. TL tuning values

\begin{tabular}{|c|c|c|c|}
\hline Controller & Kp & Ti & Td \\
\hline TL - PI & 219 & 6.58 & -- \\
\hline TL - PID & 318.54 & 6.58 & 0.47 \\
\hline
\end{tabular}


International Journal of Mathematical, Engineering and Management Sciences

Vol. 4, No. 3, 803-813, 2019

https://dx.doi.org/10.33889/IJMEMS.2019.4.3-063

Table 3. IMC tuning values

\begin{tabular}{|c|c|c|c|}
\hline Controller & Kp & $\mathrm{Ti}$ & $\mathrm{Td}$ \\
\hline IMC - PI & 166.67 & 3 & -- \\
\hline IMC - PID & 233.34 & 10.5 & 0.48 \\
\hline
\end{tabular}

Table 4. EFO tuning values

\begin{tabular}{|c|c|c|c|}
\hline Controller & Kp & Ti & Td \\
\hline EFO - PI & 230.17 & 8.17 & -- \\
\hline EFO - PID & 226.67 & 8.17 & 0.25 \\
\hline
\end{tabular}

\section{Result Analysis}

This section discusses the performance of all four controllers designed for given FOPDT process. First of all, open loop time and frequency responses of the system have been obtained and studied. Table 5 indicates the time and frequency responses of the given dead time system $(G(s))$ and its pade's approximated model $\left(G_{\text {pade's }}(s)\right)$. From the obtained open loop responses of both models it is observed that both model exhibit similar responses.

Table 5. Open loop step responses

\begin{tabular}{|c|c|c|c|c|c|}
\hline \multirow{2}{*}{ System } & \multicolumn{3}{|c|}{ Time Response } & \multicolumn{2}{c|}{ Frequency Response } \\
\cline { 2 - 6 } & Rise time & Maximum overshoot & Settling time & Gain Margin & Phase Margin \\
\hline $\mathrm{G}(\mathrm{s})$ & 21.97 & 0 & 40.12 & 54.7 & Inf \\
\hline $\mathrm{G}_{\text {Pade' }}(\mathrm{s})$ & 21.99 & 0 & 39.98 & 56.9 & Inf \\
\hline
\end{tabular}

Similarly, Figures 2(a) and 2(b) represent open loop step responses of $G(s)$ and $G_{p a d e ' s}(s)$ respectively. Likewise, Figure 3 and 4 depict bode plots of both models to know the stability margins (i.e. gain and phase margins). Figure 5 presents a comparison of Nyquist plots of both models to know the value of critical frequencies. Critical frequency is the critical point on the Nyquist plot at which Nyquist plot crosses the negative real axis. It is also known as phase crossover frequency. Critical frequency can also be determined from bode plots of the given systems. From the bode plots and Nyquist plots of given systems, it is observed that both models are open loop and closed loop stable. After studying systems as an open loop, controllers have been designed and implemented on the systems using MATLAB/Simulink. Controlled responses of both systems have been obtained for all control techniques and analyzed. All the controlled time, frequency responses and performance indices for both systems have been depicted from Table 6 to Table 9. Compared step responses of both controlled systems have been depicted in Figure 6. To know stability margins, bode plots of both controlled systems have been obtained and studied (presented in Figure 7 to 10). 
International Journal of Mathematical, Engineering and Management Sciences

Vol. 4, No. 3, 803-813, 2019

https://dx.doi.org/10.33889/IJMEMS.2019.4.3-063

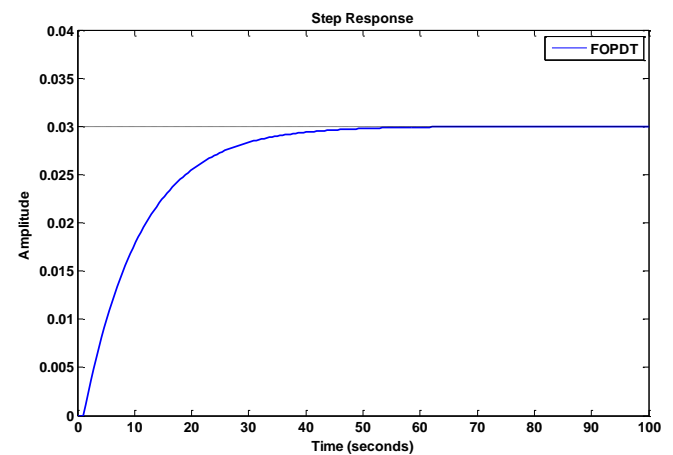

(a)

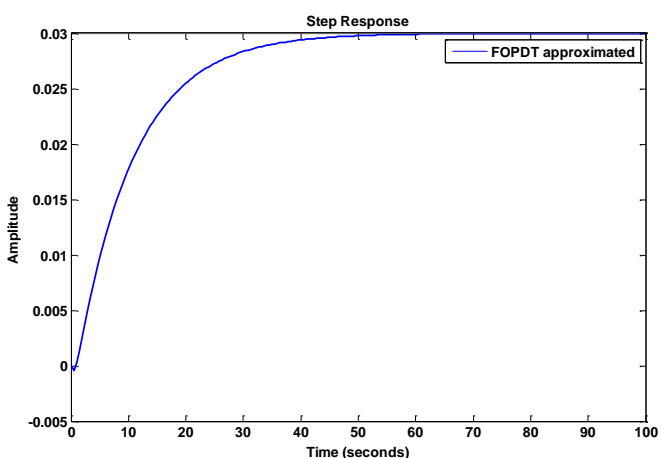

(b)

Figure 2. Open loop step response (a) G(s); (b) G $\mathrm{G}_{\text {Pade's }}(\mathrm{s})$

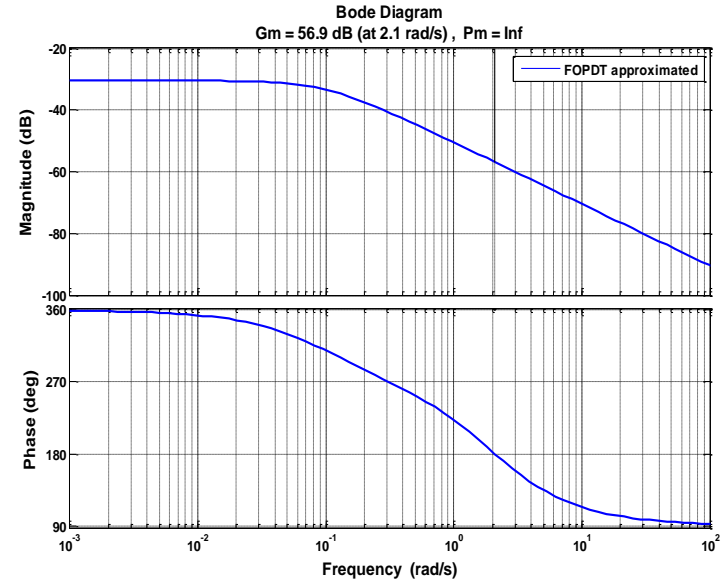

Figure 3. Bode plot of G(s)

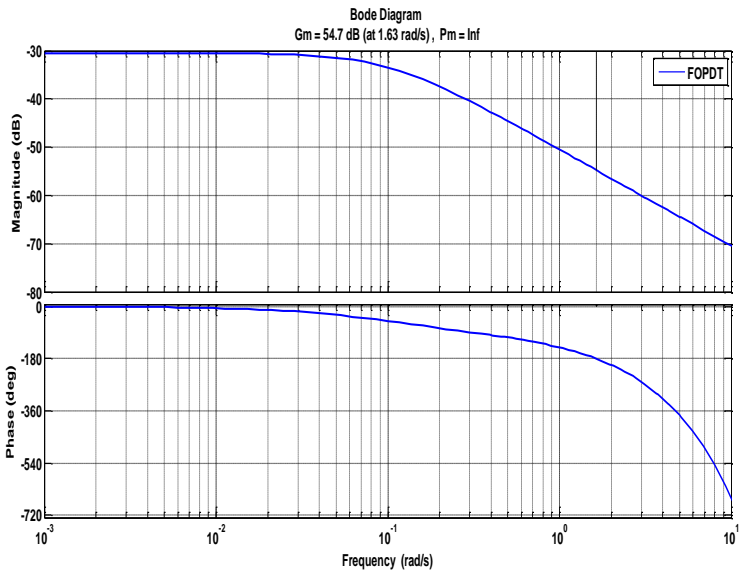

Figure 4. Bode plot of $\mathrm{G}_{\text {Pade's }}(\mathrm{s})$ 
International Journal of Mathematical, Engineering and Management Sciences

Vol. 4, No. 3, 803-813, 2019

https://dx.doi.org/10.33889/IJMEMS.2019.4.3-063

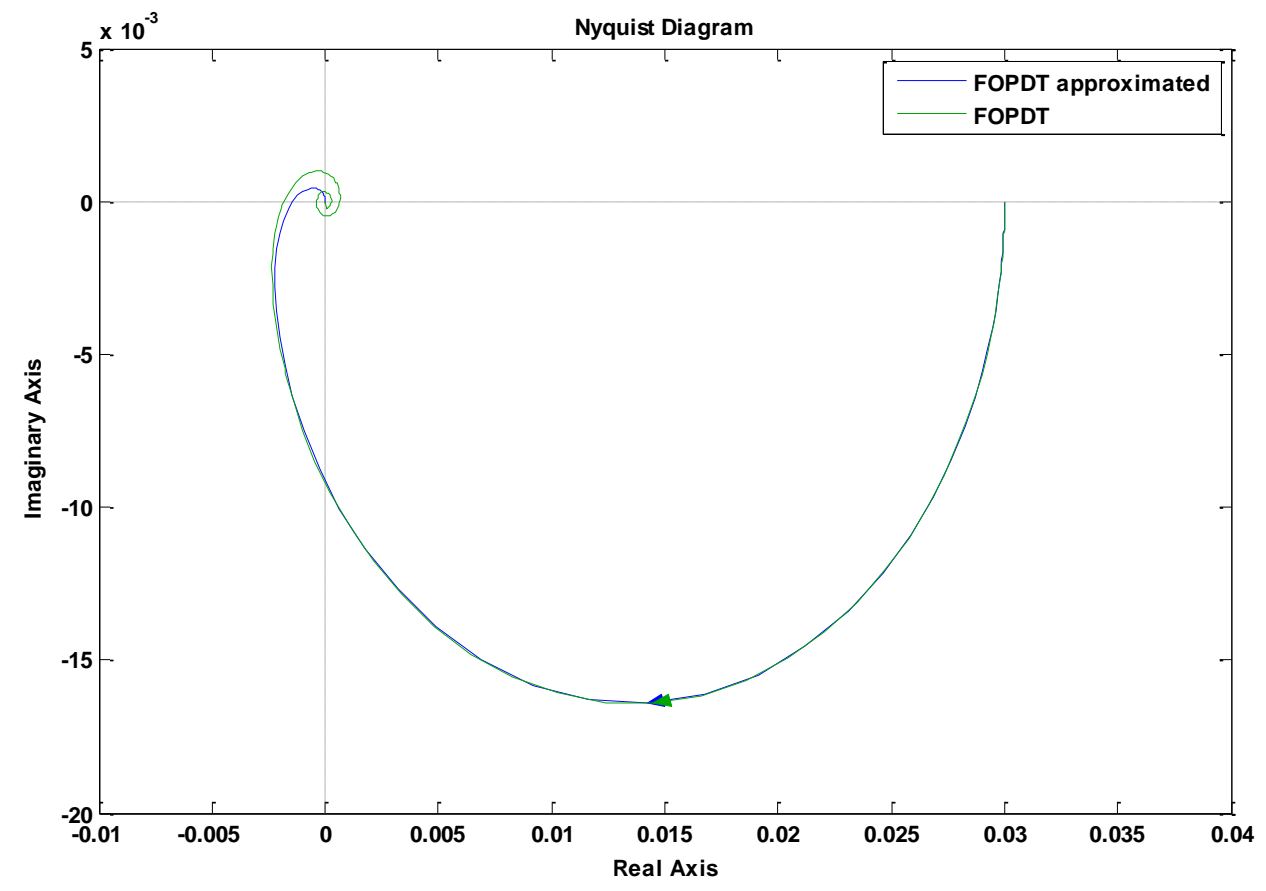

Figure 5. Bode plot comparison of G(s) and $\mathrm{G}_{\text {Pade's }}(\mathrm{s})$
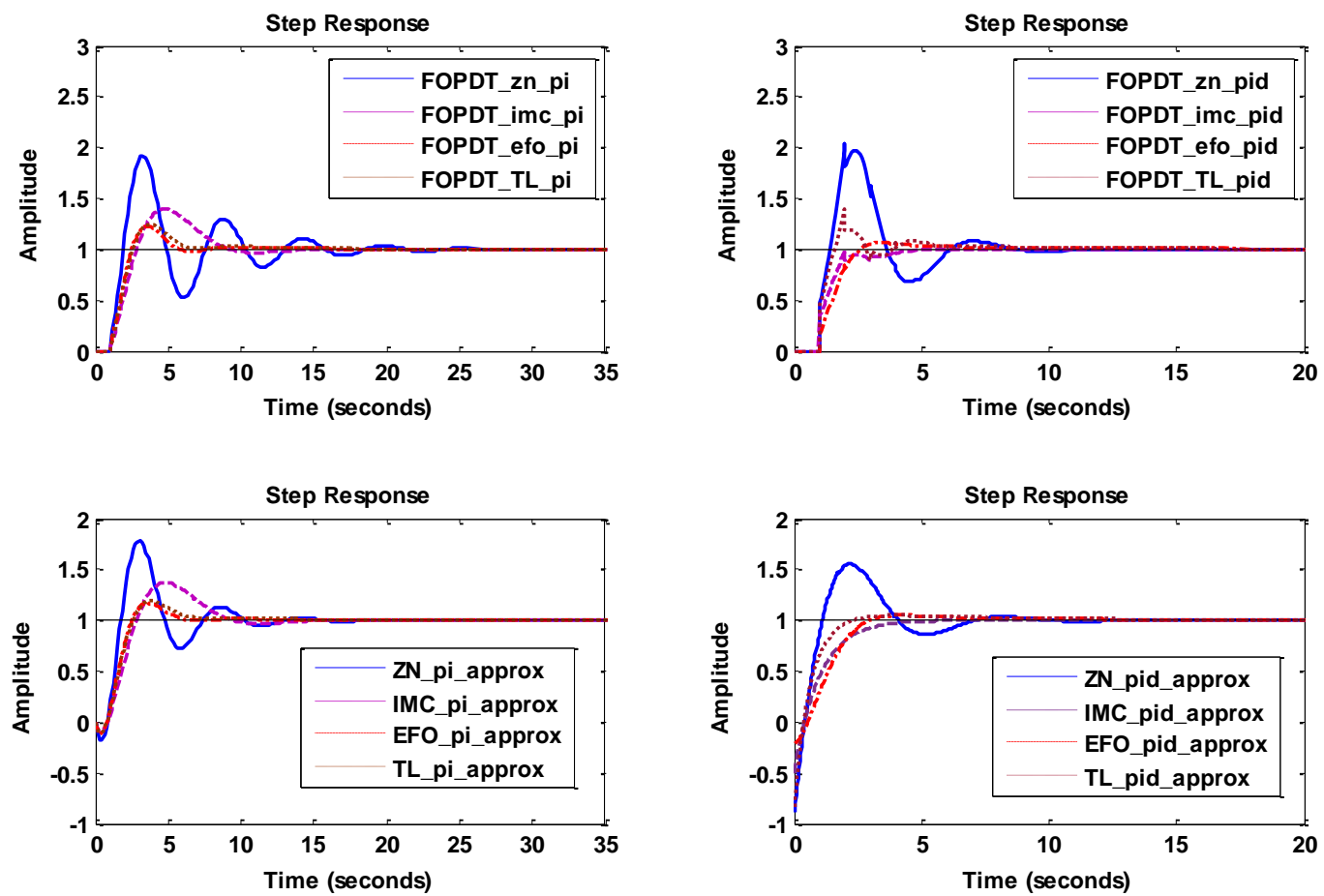

Figure 6. Comparison of step response of G(s) and $\mathrm{G}_{\text {Pade's }}(\mathrm{s})$ 
International Journal of Mathematical, Engineering and Management Sciences

Vol. 4, No. 3, 803-813, 2019

https://dx.doi.org/10.33889/IJMEMS.2019.4.3-063
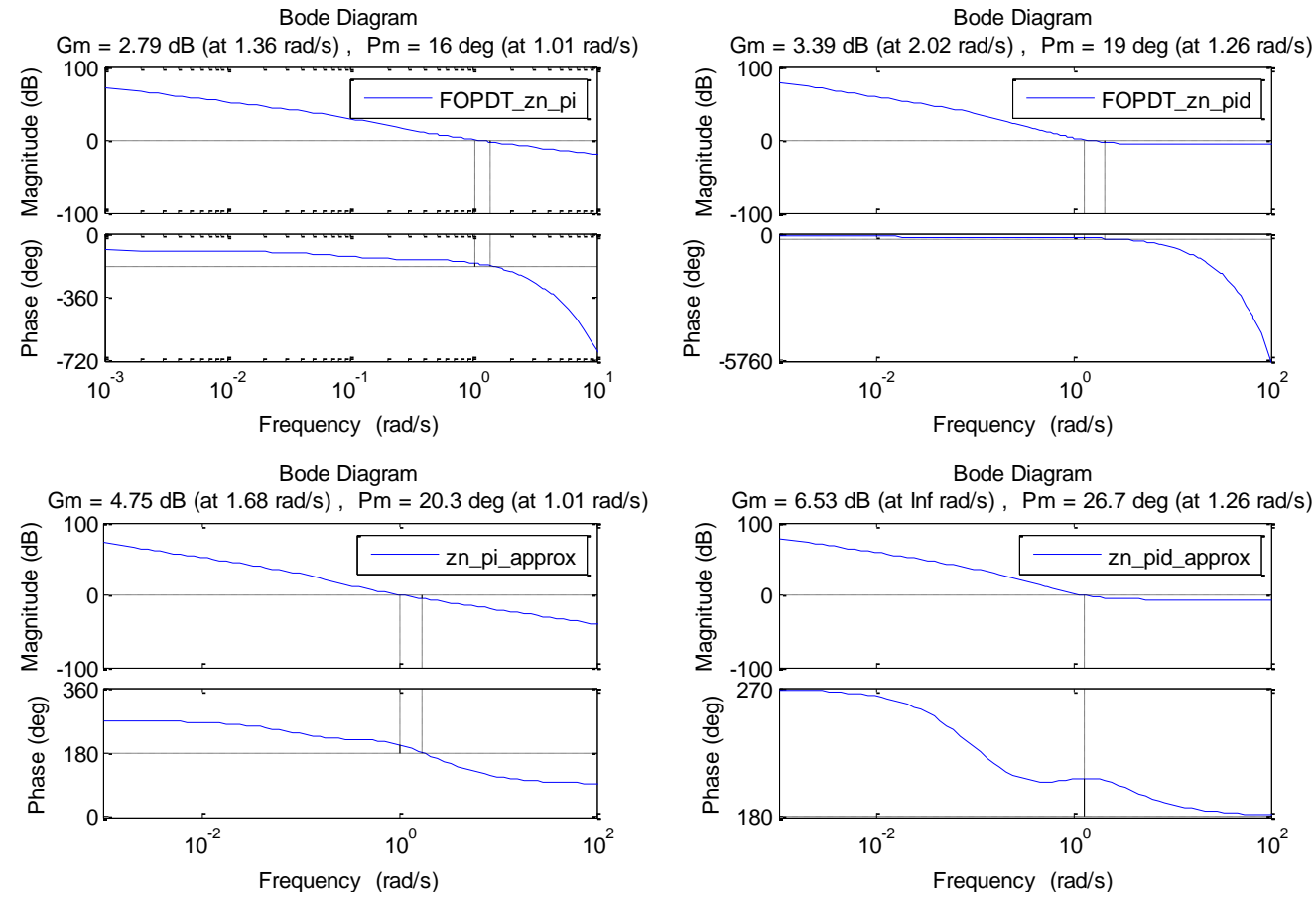

Figure 7. Bode plots of $\mathrm{G}(\mathrm{s})$ and $\mathrm{G}_{\text {Pade's }}(\mathrm{s})$ with $\mathrm{ZN}$ controller

Bode Diagram

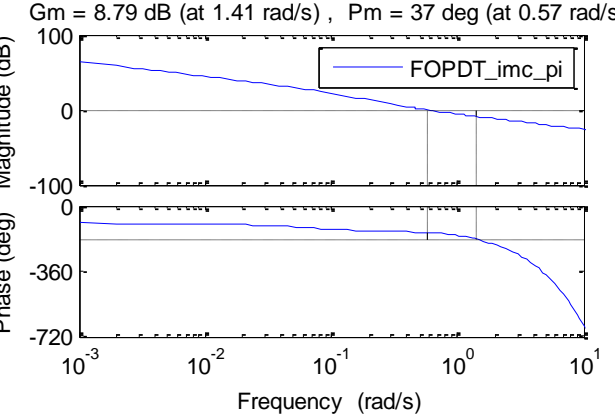

Bode Diagram

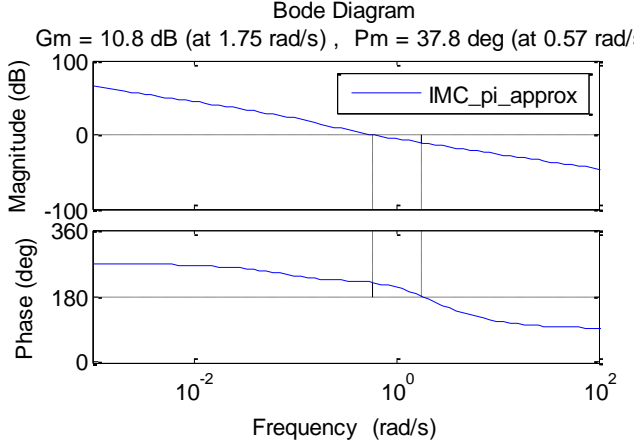

Bode Diagram

$\mathrm{Gm}=7.34 \mathrm{~dB}($ at $2.46 \mathrm{rad} / \mathrm{s}), P \mathrm{Pm}=69 \mathrm{deg}($ at $0.707 \mathrm{rad} / \mathrm{s}$ )

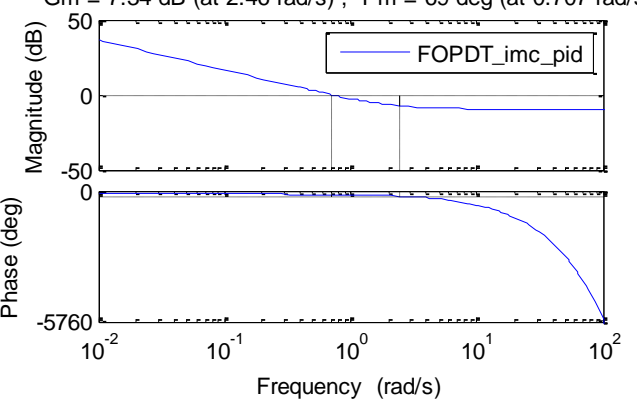

Bode Diagram

$\mathrm{Gm}=9.54 \mathrm{~dB}($ at Inf rad $/ \mathrm{s}), \mathrm{Pm}=70.5 \mathrm{deg}($ at $0.707 \mathrm{rad} / \mathrm{s})$

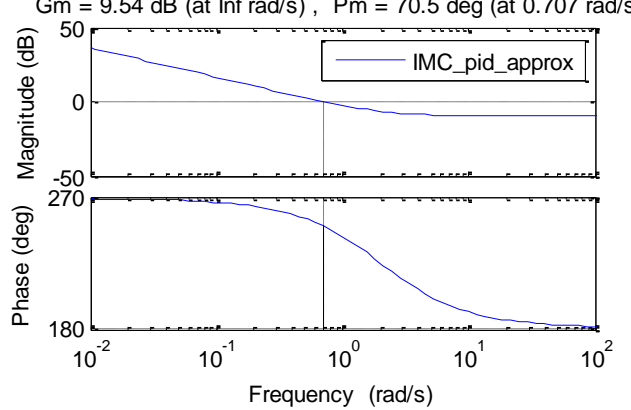

Figure 8. Bode plots of G(s) and $\mathrm{G}_{\text {Pade's }}(\mathrm{s})$ with IMC controller 
International Journal of Mathematical, Engineering and Management Sciences

Vol. 4, No. 3, 803-813, 2019

https://dx.doi.org/10.33889/IJMEMS.2019.4.3-063
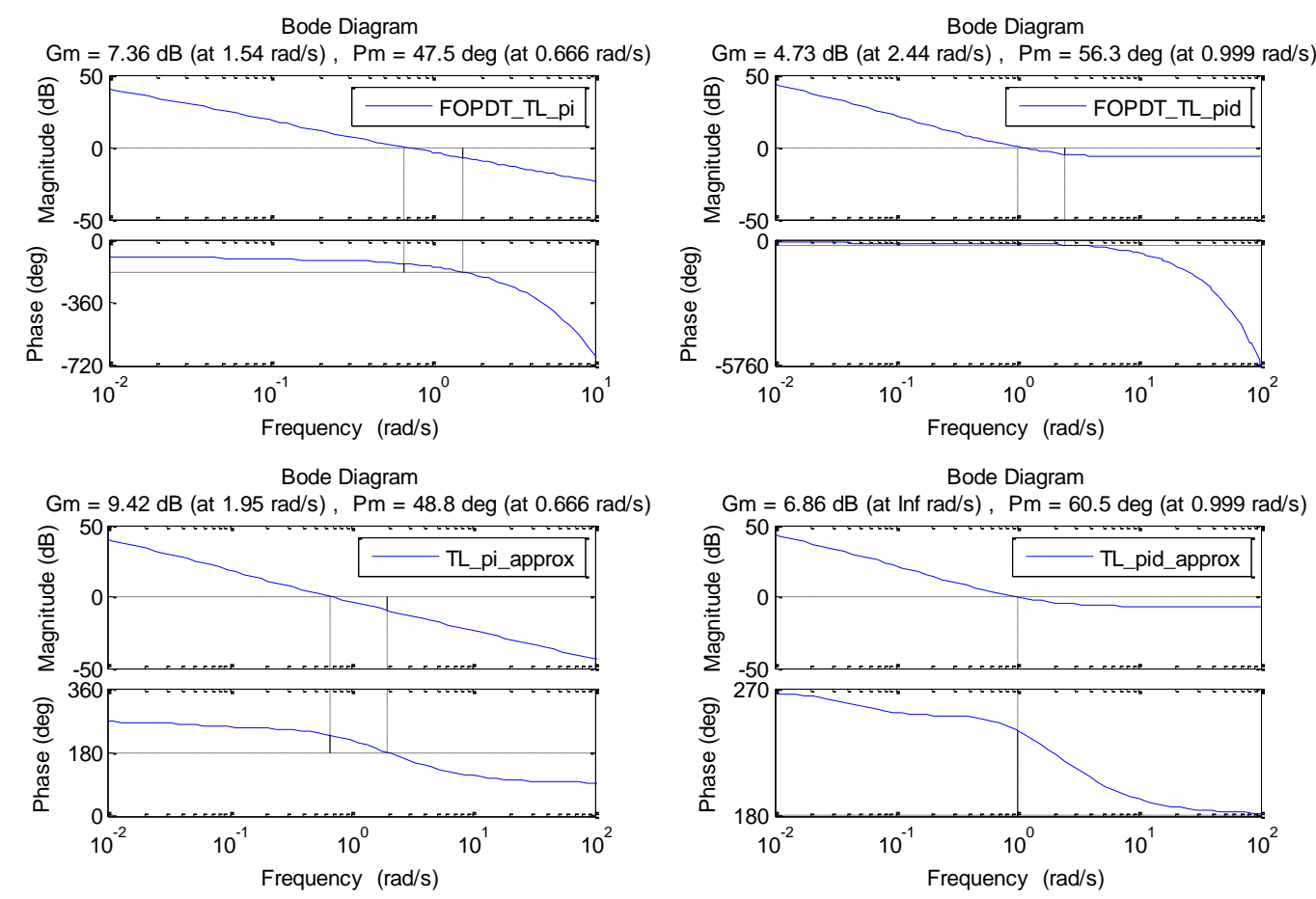

Figure 9. Bode plots of G(s) and $\mathrm{G}_{\text {Pade's }}(\mathrm{s})$ with TL controller

Bode Diagram

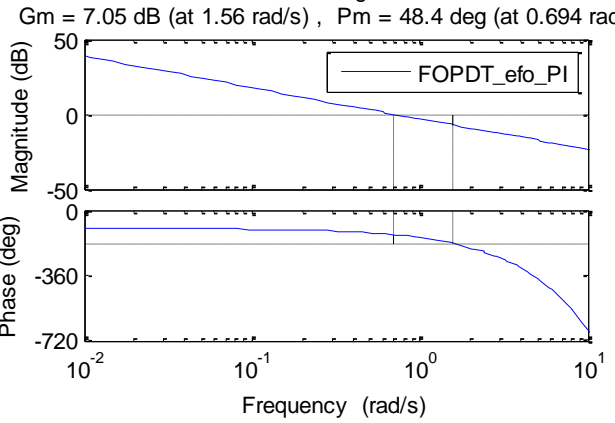

Bode Diagram

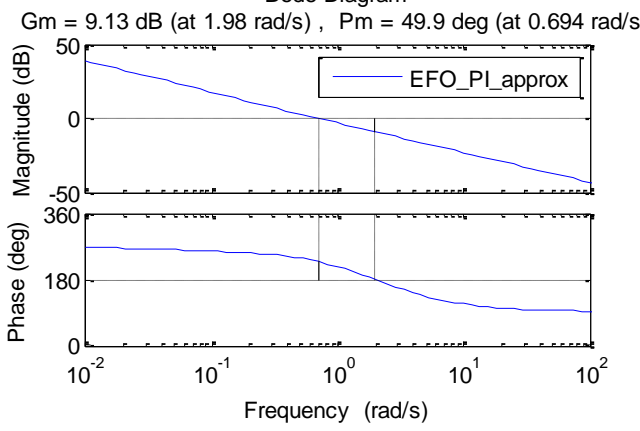

Bode Diagram

$\mathrm{Gm}=8.76 \mathrm{~dB}($ at $2.05 \mathrm{rad} / \mathrm{s}), \mathrm{Pm}=59.3 \mathrm{deg}($ at $0.673 \mathrm{rad} / \mathrm{s}$

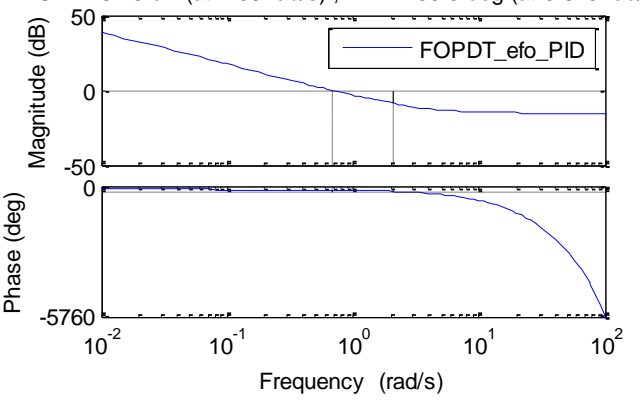

Bode Diagram

$\mathrm{Gm}=15.3 \mathrm{~dB}($ at $\operatorname{lnf} \mathrm{rad} / \mathrm{s}), \mathrm{Pm}=60.6 \mathrm{deg}$ (at $0.673 \mathrm{rad} / \mathrm{s})$

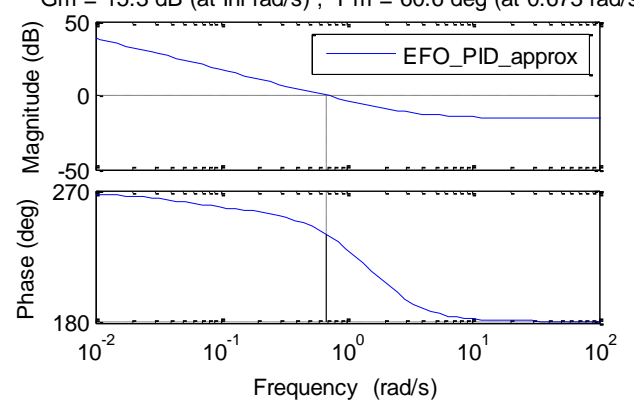

Figure 10. Bode plots of $\mathrm{G}(\mathrm{s})$ and $\mathrm{G}_{\text {Pade's }}(\mathrm{s})$ with EFO controller 
International Journal of Mathematical, Engineering and Management Sciences

Vol. 4, No. 3, 803-813, 2019

https://dx.doi.org/10.33889/IJMEMS.2019.4.3-063

Table 6. Closed loop PI - controlled responses of G(s)

\begin{tabular}{|c|c|c|c|c|c|c|c|c|c|c|}
\hline \multirow{3}{*}{ System } & \multirow{2}{*}{$\begin{array}{c}\text { Tuning } \\
\text { Technique }\end{array}$} & \multicolumn{3}{|c|}{ Time Response } & \multicolumn{2}{c|}{ Frequency Response } & \multicolumn{3}{c|}{ Performance Indices } \\
\cline { 3 - 10 } & time & $\begin{array}{c}\text { Maximum } \\
\text { overshoot }\end{array}$ & $\begin{array}{c}\text { Settling } \\
\text { time }\end{array}$ & $\begin{array}{c}\text { Gain } \\
\text { Margin }\end{array}$ & $\begin{array}{c}\text { Phase } \\
\text { Margin }\end{array}$ & ISE & IAE & ITAE & ITSE \\
\hline \multirow{4}{*}{ G(s) } & IMC - PI & 1.42 & 39.55 & 12.79 & 8.79 & 37 & 2.03 & 3.44 & 10.97 & 3.57 \\
\cline { 2 - 11 } & ZN - PI & 0.74 & 92.37 & 22.83 & 2.79 & 16 & 3.05 & 5.26 & 27.99 & 8.74 \\
\cline { 2 - 10 } & TL - PI & 1.22 & 24.54 & 11.34 & 7.36 & 47.5 & 1.60 & 2.50 & 6.69 & 1.62 \\
\cline { 2 - 11 } & EFO - PI & 1.18 & 23.09 & 9.56 & 7.05 & 48.4 & 1.56 & 2.32 & 5.44 & 1.46 \\
\hline
\end{tabular}

Table 7. Closed loop PID - controlled responses of G(s)

\begin{tabular}{|c|c|c|c|c|c|c|c|c|c|c|}
\hline \multirow{3}{*}{ System } & \multirow{2}{*}{$\begin{array}{c}\text { Tuning } \\
\text { Technique }\end{array}$} & \multicolumn{3}{|c|}{ Time Response } & \multicolumn{2}{c|}{ Frequency Response } & \multicolumn{3}{c|}{ Performance Indices } \\
\cline { 3 - 10 } & time & $\begin{array}{c}\text { Maximum } \\
\text { overshoot }\end{array}$ & $\begin{array}{c}\text { Settling } \\
\text { time }\end{array}$ & $\begin{array}{c}\text { Gain } \\
\text { Margin }\end{array}$ & $\begin{array}{c}\text { Phase } \\
\text { Margin }\end{array}$ & ISE & IAE & ITAE & ITSE \\
\hline \multirow{4}{*}{ G(s) } & IMC - PID & 0.85 & 0 & 4.36 & 7.34 & 69 & 1.13 & 1.49 & 1.49 & 0.69 \\
\cline { 2 - 11 } & ZN - PID & 0.32 & 103.5 & 8.28 & 3.39 & 19 & 2.17 & 3.08 & 7.49 & 3.62 \\
\cline { 2 - 10 } & TL - PID & 0.48 & 39.02 & 9.81 & 4.73 & 56.3 & 1.07 & 1.69 & 4.20 & 0.68 \\
\cline { 2 - 11 } & EFO - PID & 1.22 & 6.26 & 7.95 & 8.76 & 59.3 & 1.28 & 1.87 & 4.52 & 0.91 \\
\hline
\end{tabular}

Table 8. Closed loop PI - controlled responses of $\mathrm{G}_{\text {Pade's }}(\mathrm{s})$

\begin{tabular}{|c|c|c|c|c|c|c|c|c|c|c|}
\hline \multirow[b]{2}{*}{ System } & \multirow{2}{*}{$\begin{array}{c}\text { Tuning } \\
\text { Technique }\end{array}$} & \multicolumn{3}{|c|}{ Time Response } & \multicolumn{2}{|c|}{ Frequency Response } & \multicolumn{4}{|c|}{ Performance Indices } \\
\hline & & $\begin{array}{l}\text { Rise } \\
\text { time }\end{array}$ & $\begin{array}{c}\text { Maximum } \\
\text { overshoot }\end{array}$ & $\begin{array}{c}\text { Settling } \\
\text { time }\end{array}$ & $\begin{array}{c}\text { Gain } \\
\text { Margin }\end{array}$ & $\begin{array}{c}\text { Phase } \\
\text { Margin }\end{array}$ & ISE & IAE & ITAE & ITSE \\
\hline \multirow{4}{*}{$\mathbf{G}_{\text {Pade's }}(\mathbf{s})$} & IMC - PI & 1.52 & 37 & 12.85 & 10.8 & 37.8 & 1.98 & 3.35 & 10.76 & 3.28 \\
\hline & $\mathbf{Z N}-\mathbf{P I}$ & 0.72 & 77.52 & 14.35 & 4.75 & 20.3 & 2.37 & 3.72 & 12.53 & 4.34 \\
\hline & $\mathbf{T L}-\mathbf{P I}$ & 1.34 & 19.18 & 10.43 & 9.42 & 48.8 & 1.55 & 2.38 & 6.37 & 1.36 \\
\hline & EFO - PI & 1.29 & 16.86 & 5.82 & 9.13 & 48.4 & 1.50 & 2.14 & 4.77 & 1.18 \\
\hline
\end{tabular}

Table 9. Closed loop PID - controlled responses of $\mathrm{G}_{\text {Pade's }}(\mathrm{s})$

\begin{tabular}{|c|c|c|c|c|c|c|c|c|c|c|}
\hline \multirow{2}{*}{ System } & \multirow{2}{*}{$\begin{array}{c}\text { Tuning } \\
\text { Technique }\end{array}$} & \multicolumn{3}{|c|}{ Time Response } & \multicolumn{2}{|c|}{ Frequency Response } & \multicolumn{4}{|c|}{ Performance Indices } \\
\hline & & $\begin{array}{l}\text { Rise } \\
\text { time } \\
\end{array}$ & $\begin{array}{c}\text { Maximum } \\
\text { overshoot }\end{array}$ & $\begin{array}{c}\text { Settling } \\
\text { time }\end{array}$ & $\begin{array}{c}\text { Gain } \\
\text { Margin } \\
\end{array}$ & $\begin{array}{l}\text { Phase } \\
\text { Margin } \\
\end{array}$ & ISE & IAE & ITAE & ITSE \\
\hline \multirow{4}{*}{$\mathbf{G}_{\text {Pade's }}(\mathbf{s})$} & IMC - PID & 2.19 & 0 & 3.91 & 9.54 & 70.5 & 1.13 & 1.50 & 1.50 & 0.56 \\
\hline & ZN - PID & 0.86 & 55.25 & 6.62 & 6.53 & 26.7 & 1.56 & 2.25 & 4.87 & 1.42 \\
\hline & TL - PID & 1.28 & 4.73 & 6.22 & 6.86 & 60.5 & 1.03 & 1.41 & 3.64 & 0.36 \\
\hline & EFO - PID & 1.89 & 4.87 & 6.93 & 15.3 & 60.6 & 1.26 & 1.83 & 4.45 & 0.77 \\
\hline
\end{tabular}


International Journal of Mathematical, Engineering and Management Sciences

Vol. 4, No. 3, 803-813, 2019

https://dx.doi.org/10.33889/IJMEMS.2019.4.3-063

\section{Conclusion}

This work has presented a comparative analysis of the performance of four controller tuning techniques for a FOPDT system and its approximated model. Performance comparison of controllers is conducted based on various responses such as time responses, frequency responses and performance indices. From the results obtained and as discussed, it is observed that as compared to conventional $\mathrm{ZN}$ and TL tuning techniques, IMC and EFO techniques give better performance. Though, EFO technique is designed for plants without ultimate points, however, it still performs better for systems with ultimate points and dead time processes.

\section{Conflict of Interest}

This is to state that there is no conflict of interest for this research article. Equal contribution for each author.

\section{Acknowledgement}

Authors would like to thank Graphic Era Deemed to be University, Dehradun for providing suitable and healthy environment for research work.

\section{References}

Bazanella, A.S., Pereira, L.F.A., \& Parraga, A. (2017). A new method for PID tuning including plants without ultimate frequency. IEEE Transactions on Control Systems Technology, 25(2), 637-644.

Chaturvedi, M., \& Juneja, P. (2013, September). Effect of dead time approximation on controller performance designed for a second order delayed model. In 2013 International Conference on Advanced Electronic Systems (ICAES) (pp. 313-315). IEEE.

Chauhaan, P., Juneja, P.K., \& Chaturvedi, M. (2014, September). Controller design and its performance analysis for a delayed process model. In 2014 International Conference on Advances in Computing, Communications and Informatics (ICACCI) (pp. 859-862). IEEE.

Chien, I.L., \& Fruehauf, P.S. (1990). Consider IMC tuning to improve controller performance. Chemistry Engineering Progress, 86(10), 33-41.

Juneja, P.K., \& Ray, A.K. (2013). Robustness analysis of various controllers designed for consistency of a headbox. Journal of Forest Products \& Industries, 2(6), 14-17.

Juneja, P.K., Ray, A.K., \& Mitra, R. (2010). Various controller design and tuning methods for a first order plus dead time process. International Journal of Computer Science \& Communication, 1(2), 161-165.

Luyben, M.L., \& Luyben, W.L. (1997). Essentials of process control. McGraw-Hill. ISBN: 0070391726, 0070391734

Luyben, W.L. (1996). Tuning proportional-integral-derivative controllers for integrator/deadtime processes. Industrial \& Engineering Chemistry Research, 35(10), 3480-3483.

Morari, M., \& Zafiriou, E. (1989). Robust process control. Prentice-Hall, Inc., Englewood Cliffs, NJ, pp 488. 
International Journal of Mathematical, Engineering and Management Sciences

Vol. 4, No. 3, 803-813, 2019

https://dx.doi.org/10.33889/IJMEMS.2019.4.3-063

Naithani, D., Chaturvedi, M., \& Juneja, P.K. (2017, December). Integral error based controller performance comparison for a FOPDT model. In 2017 Fourth International Conference on Image Information Processing (ICIIP) (pp. 1-4). IEEE.

Normey-Rico, J.E. (2007). Control of dead-time processes. Springer Science \& Business Media, 9-53.

O'Dwyer, A. (2006). PI and PID controller tuning rules: an overview and personal perspective. IET Irish Signals and Systems Conference, 161-166.

Rivera, D.E., Morari, M., \& Skogestad, S. (1986). Internal model control: PID controller design. Industrial \& Engineering Chemistry Process Design and Development, 25(1), 252-265.

Saxena, S., \& Hote, Y.V. (2016). Simple approach to design PID controller via internal model control. Arabian Journal for Science and Engineering, 41(9), 3473-3489.

Schneider, D.M. (1988). Control of processes with time delays. IEEE Transactions on Industry Applications, 24(2), 186-191.

Sell, N.J. (1995). Process control fundamentals for the pulp and paper industry. Technical Association of the Pulp \& Paper Industry.

Shi, J., \& Lee, W.S. (2002, October). IMC-PID controllers for first-order plus dead-time processes: a simple design with guaranteed phase margin. In 2002 IEEE Region 10 Conference on Computers, Communications, Control and Power Engineering, TENCOM'02, Proceedings. (Vol. 3, pp. 13971400). IEEE.

Skogestad, S. (2003). Simple analytic rules for model reduction and PID controller tuning. Journal of Process Control, 13(4), 291-309.

Tyreus, B.D., \& Luyben, W.L. (1992). Tuning PI controllers for integrator/dead time processes. Industrial \& Engineering Chemistry Research, 31(11), 2625-2628.

Vilanova, R., \& Balaguer, P. (2006, October). ISA-PID controller tuning: a combined min-max/ISE approach. In 2006 IEEE Conference on Computer Aided Control System Design, 2006 IEEE International Conference on Control Applications, 2006 IEEE International Symposium on Intelligent Control (pp. 2956-2961). IEEE.

Ziegler, J.G., Nichols, N.B., \& Rochester, N.Y. (1942). Optimum settings for automatic controllers. Transactions of the A.S.M.E, 64(11), 759-765. 